\title{
A New Effective Robust Nonlinear Controller Based on PSO for Interleaved DC-DC Boost Converters for Fuel Cell Voltage Regulation
}

\author{
Samir Abdelmalek ${ }^{1}$, Ali Dali ${ }^{2}$, Maamar Bettayeb ${ }^{3}$, Azzeddine Bakdi $^{4}$ \\ ${ }^{1}$ Faculty of Technology, Department of Electrical Engineering, University of Medea, Algeria; \\ Email: samir aut@yahoo.fr \\ ${ }^{2}$ Renewable Energy Development Center (CDER), Algeria. \\ Email: a.dali@cder.dz
}

${ }^{3}$ Department of Electrical and Computer Engineering, University of Sharjah, United Arab Emirates, and Center of Excellence in Intelligent Engineering Systems (CEIES), King Abdulaziz Univeristy, Jeddah, KSA.

Email: maamar@sharjah.ac.ae

${ }^{4}$ Department of Mathematics, University of Oslo, 0851 Oslo, Norway

Email: bkdaznsun@gmail.com

\begin{abstract}
:
Output voltage regulation of DC-DC converters has recently gained an increasing attention to face the many system nonidealities. The fast switching behaviour is nonlinear time-varying, the presence of model and measurement uncertainties, and large variations, are all inherited challenges. The aim of the present work is to design a robust nonlinear controller that ensures satisfactory and robust output voltage regulation for a Proton-Exchange Membrane Fuel Cell (PEMFC) based on a DC-DC Interleaved Boost Converter (IBC). A state space model of the DC-DC IBC is first derived using the state space averaging technique and a mathematical model is constructed for the PEFMC. In this regard, a robust nonlinear controller and a Proportional Integral (PI) controller are proposed. The controllers are tuned though Particle Swarm Optimization (PSO) algorithm to estimate their good parameters assuring the desired performance is met. The Integral of Absolute Error (IAE) criterion is used to improve the dynamic performance of the overall controlled system. Furthermore, the closed loop stability is analysed using the Lyapunov stability theorem, and the effectiveness of the closed-loop system is validated under various operating
\end{abstract}


conditions of the PEMFC and load perturbations. Compared to other methods, the obtained results demonstrate a superior performance of the proposed control strategy in terms of its robustness to variations and uncertainties, smooth tracking of a varying set-point and faster transients.

Keywords - Interleaved boost converter; Proton-Exchange Membrane Fuel Cell; PSO algorithm; Nonlinear control; PSO-PI controller; Current ripples.

\section{Nomenclature}

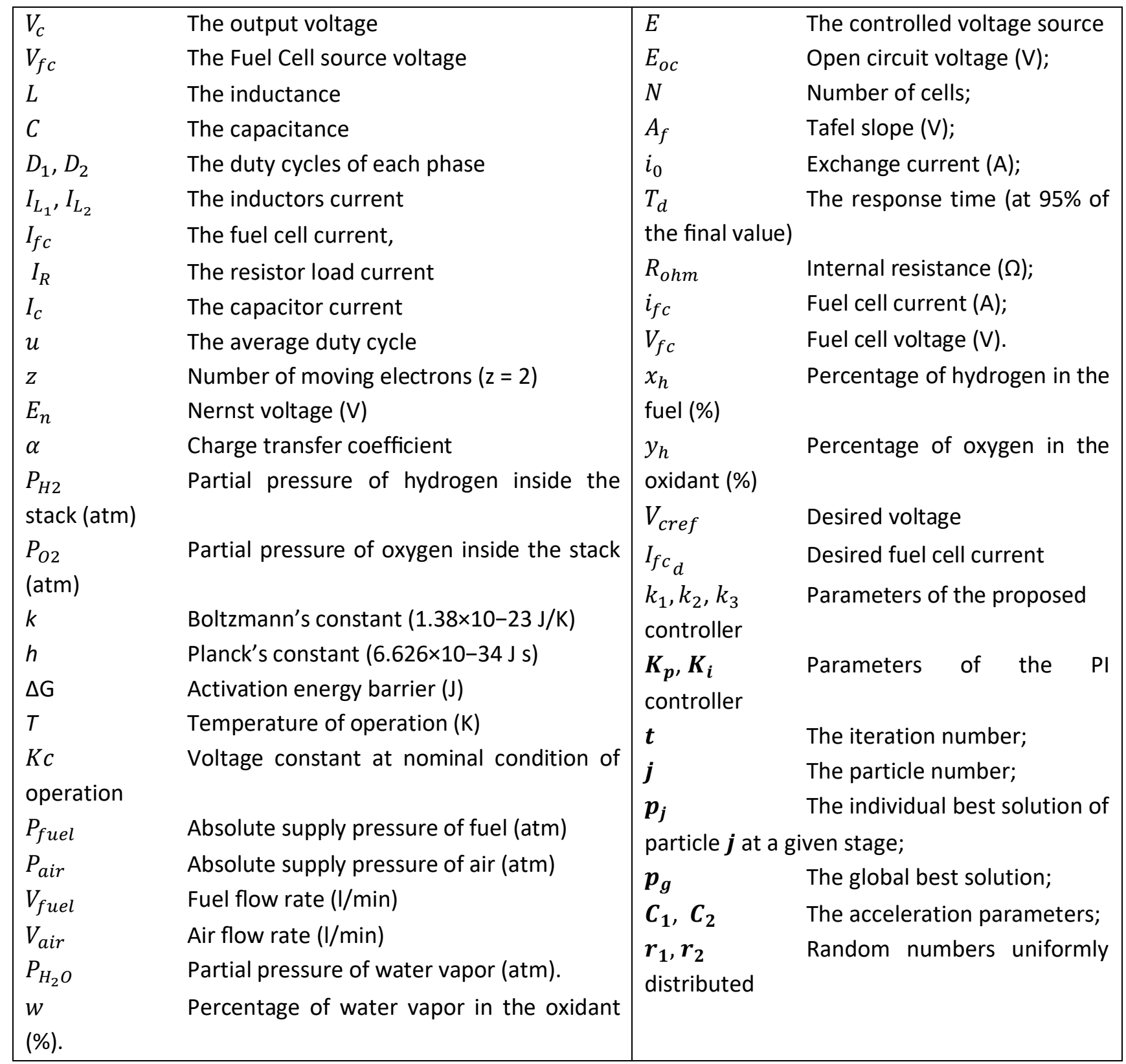




\section{Abbreviations}

$\begin{array}{ll}\text { PEMFC } & \text { Proton-Exchange Membrane Fuel Cell } \\ \text { IBC } & \text { Interleaved Boost Converter } \\ \text { PI } & \text { Proportional Integral } \\ \text { PSO } & \text { Particle Swarm Optimization } \\ \text { IAE } & \text { Integral of Absolute Error } \\ \text { FCS } & \text { Fuel Cells } \\ \text { EVs } & \text { Electric Vehicles } \\ \text { MPC } & \text { Model Predictive Control } \\ \text { LTI } & \text { Linear Time-Invariant } \\ \text { PSO-PIC } & \text { PSO-tuned PI controller } \\ \text { PSO-RNC } & \text { PSO-tuned robust nonlinear controller }\end{array}$

\section{1- Introduction}

In the last few decades, Fuel Cells (FCs) have emerged as a potential alternative solution to fossilfuel energy sources [1]. In addition, they are considered among the most promising technologies for electrical power generation [2]. Fuel cells are capable of converting chemical energy directly into electrical energy, without any intermediate step. The electrical efficiency of FCs is therefore considerably higher than the other traditional sources for generating electrical power. Fuel cells are widely used in a broad range of applications, and mainly in the transport industry and electric Vehicles (EVs) [3] as a replacement for conventional engines. FCs are also used for low power generation as they offer many advantages such as low operating temperature, fast response to load changes, high power density, low corrosion, very low noise and environmental friendliness [1, $2,4,5]$. Types as well as advantages and drawbacks of fuel cell membranes are all summarized in [6]. However, the connection of FC elements and the system operation should accomplish technical qualifications to ensure a high-power quality and reliable generation [7, 33]. Power quality problems may cause many effects such as irregular switching $[39,40]$, hardware damages [41], and overheating; and while the FC output voltage and power are highly dependent on the connected load, effective and robust controllers of FC converters must be adopted to control the power flow and maintain a smooth and safe power generation. 
DC-DC boost converters are usually required in industrial power applications of low output voltage such as renewable energy sources. Due to their increasing scope of utilization, these devices are becoming a subject of increasing interest, and they are classified into many different topologies [8, 9]. In general, DC-DC converters are employed to adapt the voltage and current levels between sources and loads while guarantying a low power loss in power generation systems [10, 11]. The DC-DC converter is an essential part of the fuel cell power generation to control the delivered power/voltage. Incorporating PEMFC dynamics with a classical DC-DC converter makes the voltage regulation task quite challenging [12]. In this context, the interleaved boost DC-DC converter (IBC) can be used [13] to meet this challenge. The IBC is considered as a good solution due to its merits, such as high efficiency, increasing the power level and minimizing the current stress on the power switches $[14,32]$. IBCs also reduce the current ripple in the input and output circuits, manage the high FC current by sharing between two legs, have a soft switching through a quasi-resonance technique, and have a fault tolerant capability in case of a power switch fault [15]. Other advantages of the IBCs are their faster dynamics, light weight, higher efficiency, and low input voltage applications.

With regard to the literature, different kinds of control strategies were employed for interleaved boost DC-DC converters for different applications such as adaptive control [16], robust control [10], nonlinear model predictive control (MPC) [17], state feedback control [18, 25], sliding mode fuzzy PID control [19], robust adaptive neural network control [20, 21], adaptive sliding mode control [22, 23], intelligent control [24], and Optimal Robust Linear Quadratic Regulator (LQR) [26]. However, among the aforementioned control techniques, the problem of designing an optimal robust nonlinear controller was not reported before. Therefore, the aim of this work is to design a robust and highly effective nonlinear control law based on PSO algorithm. The objective of the design is to address the system nonlinear time varying behaviour, aim for optimal performance in face of large variability, and increase robustness to uncertainties and disturbances.

The contributions of this work can be highlighted as follows: i) Use of a new topology based on DCDC IBC rather than the classical boost DC-DC converter for improving fuel cell output regulation, ii) Design and validation of a novel robust nonlinear controller for output voltage regulation under varying loading conditions, iii) The proposed strategy and the controller have their parameters 
tuned using PSO algorithm, and iv) Validation and comparison of the proposed controller design against other techniques.

The remaining of this paper is organized as follows. Analytical modelling of the physical DC-DC IBC system is firstly introduced in Section 2 . Section 3 then presents a mathematical model for the fuel cell and the entire system as shown in Fig. 1. A step by step design of the nonlinear controller is detailed in Section 4. Section 5 is dedicated to parameter optimization using the PSO algorithm for both robust nonlinear and conventional PI controllers. Validation and test results are presented in three scenarios and discussed in Section 6 in addition to comparisons. The key aspects of this paper are summarized in the last section including also some concluding remarks and suggestions for future work.

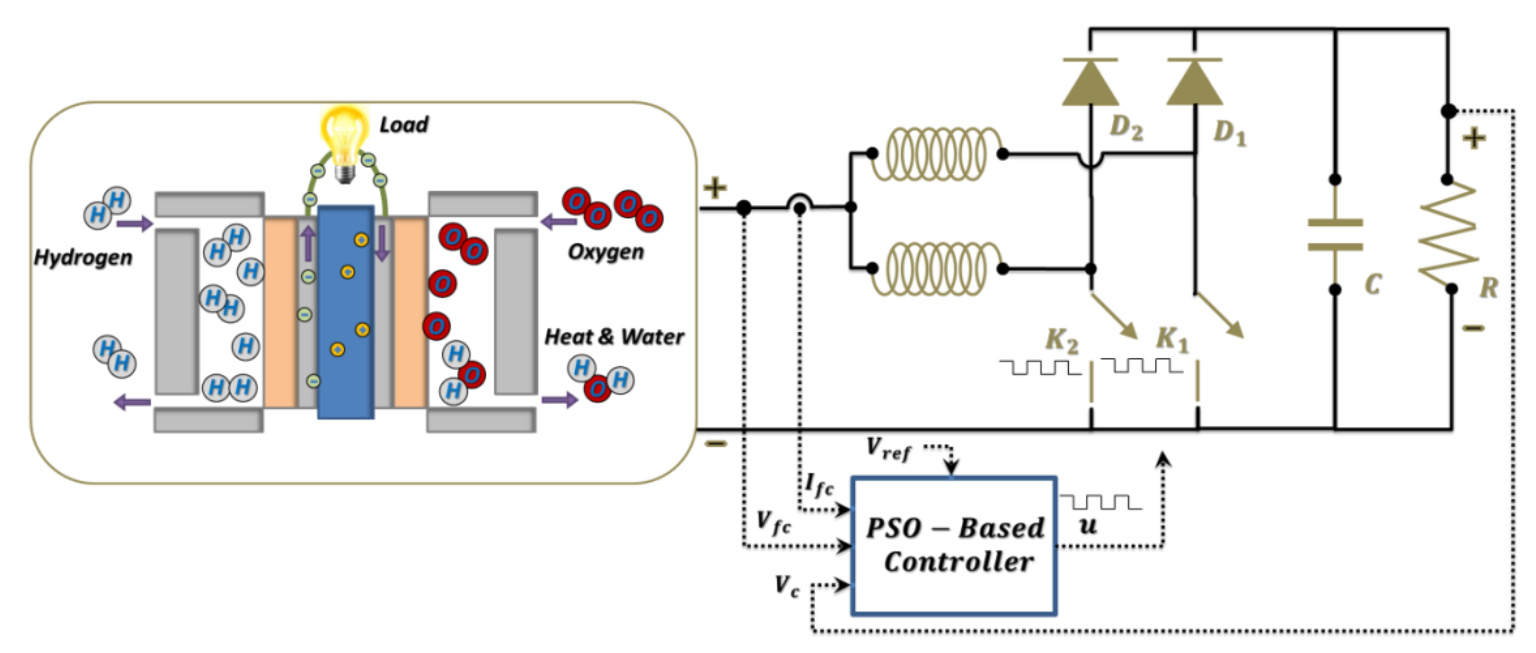

Fig 1. Simplified structure of the PEMFC-DC-DC-IBC system.

\section{2- Developed State Space Model of the IBC}

Recently, IBCs are often used in various energy systems and applications of low output voltage, mainly as power electronic interfaces in renewable energy sources such as photovoltaic power systems and fuel cells. Fig. 2 represents a schematic diagram of a DC-DC interleaved boost converter versus a classical DC-DC boost converter. $V_{c}$ is the output voltage and $V_{f c}$ is the Fuel Cell source voltage, the IBC is similar to a classical boost converter but contains two current inductances and controlled by two switches.

State-space averaging is an alternative representation in which the converter is considered to operate in ON and OFF modes. A non-linear model is constructed to represent the operation for 
each mode and a unified average state-space model is obtained for the converter. The average model of the interleaved boost DC-DC converter is the same as the traditional boost DC-DC converter except that it contains two current inductors [26]. The dynamics of the IBC converter are represented by [26]:

$$
\left\{\begin{array}{c}
L_{1} \frac{d I_{L_{1}}}{d t}=V_{f c}-V_{c}\left(1-D_{1}\right) \\
L_{2} \frac{d I_{L_{2}}}{d t}=V_{f c}-V_{c}\left(1-D_{2}\right) \\
C \frac{d V_{c}}{d t}=I_{L_{1}}\left(1-D_{1}\right)+I_{L_{2}}\left(1-D_{2}\right)-I_{R}
\end{array}\right.
$$

such that:

$$
\left\{\begin{array}{c}
I_{f c}=I_{L_{1}}+I_{L_{2}} \\
D_{1}=D_{2}=1-u \\
L_{1}=L_{2}=L
\end{array}\right.
$$

where $L$ and $C$ are respectively the inductance and the capacitance, $D_{1}$ and $D_{2}$ are the duty cycles of each phase (one is shifted by a half period from the other). $I_{L_{1}}$ and $I_{L_{2}}$ are the inductors currents, $I_{f c}$ is the fuel cell current, $I_{R}=V_{c} / R$ is the resistor $(R)$ load current and $I_{c}$ is the capacitor current.

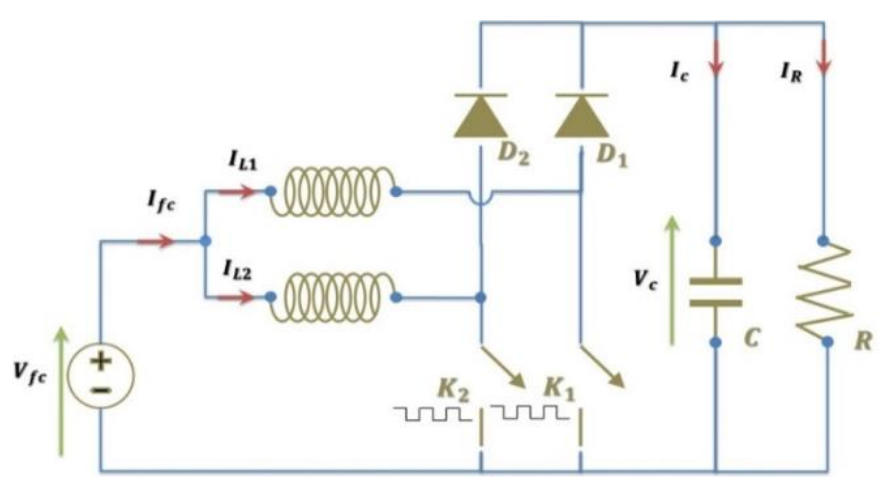

(a)

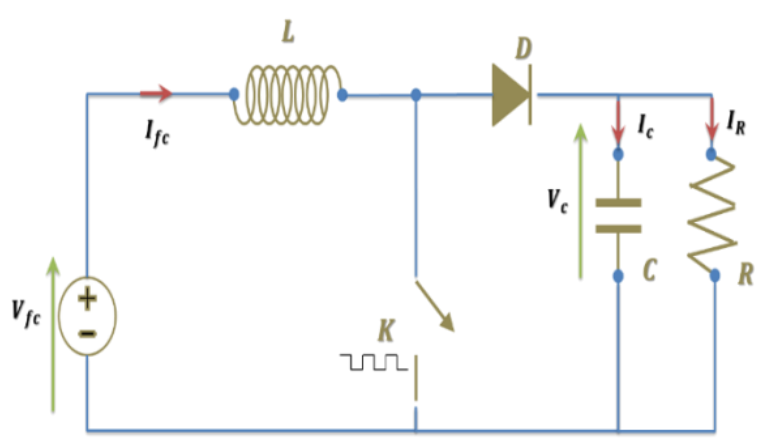

(b)

Fig 2. Voltage regulation of : (a) the fuel cell interleaved DC-DC boost converter, (b) DC-DC boost converter.

The average model of System (1) may then be expressed as follows:

$$
\left\{\begin{array}{l}
\dot{I}_{f c}=\frac{2}{L} V_{f c}-\frac{2}{L} V_{c} u \\
\dot{V}_{c}=\frac{1}{C} I_{f c} u-\frac{1}{R C} V_{c}
\end{array}\right.
$$

where $u$ is the average duty cycle. 
The system state space vector $x=\left[\int V_{c}, V_{c}, I_{f c}\right]^{T}$ includes the measurable output voltage $\left(V_{c}\right)$ and the fuel cell current $\left(I_{f c}\right)$ (shown in Fig.2), the other state $\left(\int V_{c}\right)$ is introduced to improve the robustness of the controller design. The augmented nonlinear model is then described as:

$$
\left\{\begin{array}{l}
\dot{x}_{1}=x_{2} \\
\dot{x}_{2}=-\frac{1}{R C} x_{2}+\frac{1}{C} x_{1} u \\
\dot{x}_{3}=-\frac{2}{L} x_{2} u+\frac{2}{L} V_{f C}
\end{array}\right.
$$

where $x_{1}=\int V_{c}, x_{2}=V_{c}$ and $x_{3}=I_{f c}$.

Manipulating the system of Eq (4), the average state-space model can be written as:

$$
\dot{x}(t)=\mathcal{A} X(t)+\mathcal{B} u(t)+\mathcal{T}
$$

where the associated matrices are given by:

$$
\mathcal{A}=\left[\begin{array}{ccc}
0 & 1 & 0 \\
0 & -\frac{1}{R C} & 0 \\
0 & 0 & 0
\end{array}\right], \mathcal{B}=\left[\begin{array}{c}
0 \\
\frac{1}{C} x_{1} \\
-\frac{2}{L} x_{2}
\end{array}\right], \mathcal{X}=\left[\begin{array}{l}
x_{1} \\
x_{2} \\
x_{3}
\end{array}\right], \mathcal{T}=\left[\begin{array}{c}
0 \\
0 \\
\frac{2}{L} V_{f c}
\end{array}\right]
$$

\section{3- Fuel Cell Mathematical Model}

In this section, a complete mathematical model is constructed to represent a fuel cell stack through a controlled voltage source in series with a constant resistance as shown in Fig. 3.

The controlled voltage source $(E)$ is expressed as [27]:

$$
\left\{\begin{array}{c}
E=E_{o c}-N A \ln \left(\frac{i_{f c}}{i_{0}}\right) \frac{1}{s \frac{T_{d}}{3}+1} \\
V_{f c}=E-R_{o h m} i_{f c}
\end{array}\right.
$$

where,

$E_{o c}$ : open circuit voltage (V);

$N$ : number of cells;

$A$ : Tafel slope (V);

$i_{0}$ : exchange current $(\mathrm{A})$;

$T_{d}$ : the response time (at $95 \%$ of the final value) (sec); 
$R_{\text {ohm }}$ : internal resistance $(\Omega)$;

$i_{f c}$ : fuel cell current (A);

$V_{f c}:$ fuel cell voltage $(\mathrm{V})$.

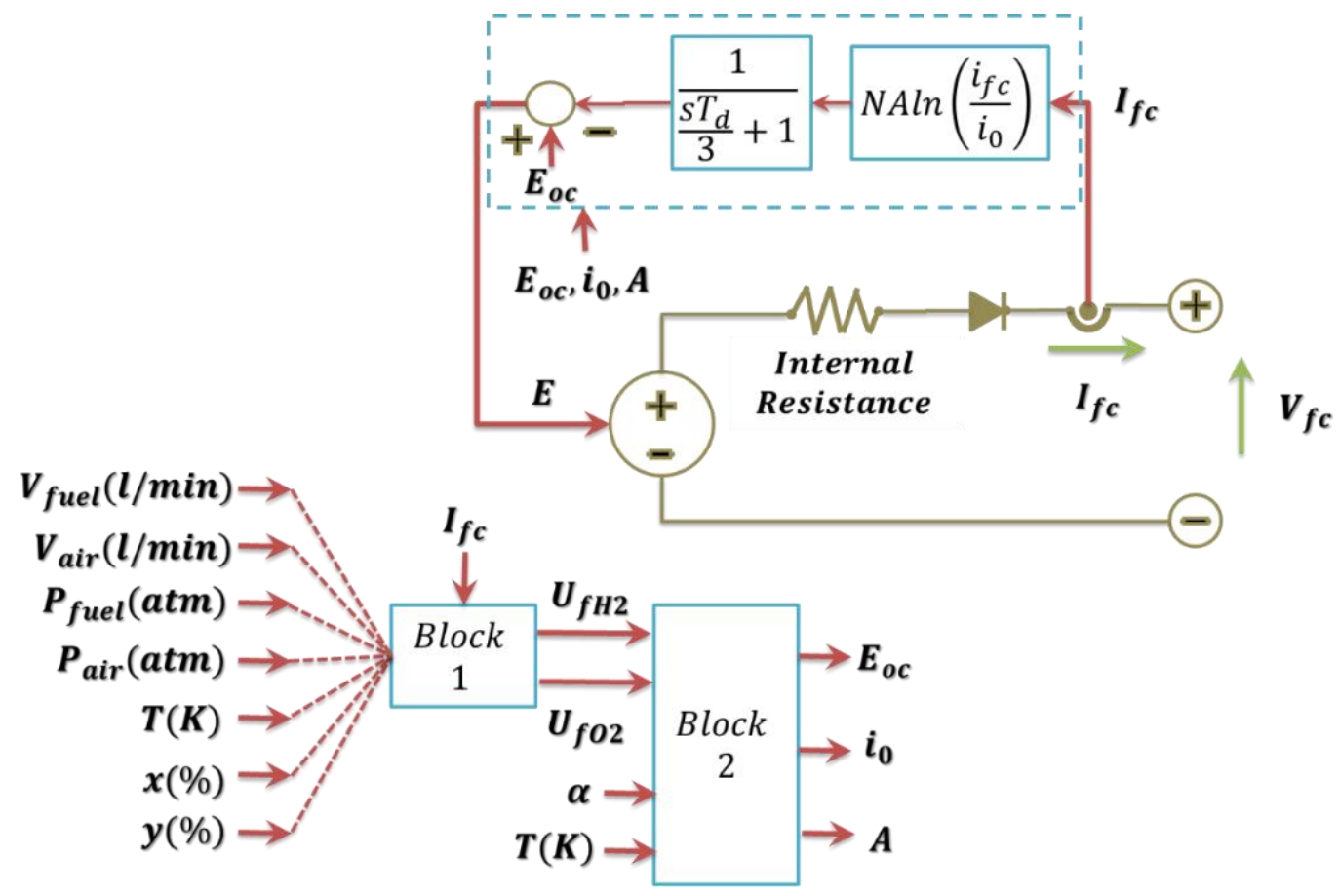

Fig 3. Fuel cell stack model.

The open circuit voltage $E_{o c}$, the Tafel slope $A$ and the exchange current $i_{0}$ are expressed as follows:

$$
\left\{\begin{array}{c}
E_{o c}=K_{c} E_{n} \\
i_{0}=\frac{z F k\left(P_{H 2}+P_{O 2}\right)}{R h} \exp \left(\frac{-\Delta G}{R T}\right) \\
A=\frac{R T}{z \alpha F}
\end{array}\right.
$$

where

$R=8.3145 \mathrm{~J} /(\mathrm{mol} \mathrm{K})$

$F=96485 \mathrm{~A} \mathrm{~s} / \mathrm{mol}$

$z=$ number of moving electrons $(z=2)$

$E_{n}=$ Nernst voltage $(\mathrm{V})$

$\alpha=$ charge transfer coefficient

$P_{H 2}=$ partial pressure of hydrogen inside the stack (atm)

$P_{O 2}=$ partial pressure of oxygen inside the stack (atm) 
$k=$ Boltzmann's constant $(1.38 \times 10-23 \mathrm{~J} / \mathrm{K})$

$h=$ Planck's constant $(6.626 \times 10-34 \mathrm{~J} \mathrm{~s})$

$\Delta \mathrm{G}=$ activation energy barrier (J)

$T=$ temperature of operation $(\mathrm{K})$

$K c=$ voltage constant at nominal condition of operation

The rates of conversion of hydrogen $\left(U_{f H_{2}}\right)$ and oxygen $\left(U_{f O 2}\right)$ are determined in Block 1 in Fig. 3 as follows $[21,27]$ :

$$
\left\{\begin{array}{c}
U_{f H 2}=\frac{60000 R T i_{f c}}{z F P_{f u e l} V_{f u e l} x_{h} \%} \\
U_{f O 2}=\frac{60000 R T i_{f c}}{z F P_{\text {air }} V_{\text {air }} y_{h} \%}
\end{array}\right.
$$

where

$$
\begin{aligned}
& P_{\text {fuel }}=\text { absolute supply pressure of fuel (atm) } \\
& P_{\text {air }}=\text { absolute supply pressure of air (atm) } \\
& V_{\text {fuel }}=\text { fuel flow rate }(\mathrm{l} / \mathrm{min}) \\
& V_{\text {air }}=\text { air flow rate }(\mathrm{l} / \mathrm{min}) \\
& x_{h}=\text { percentage of hydrogen in the fuel (\%) } \\
& y_{h}=\text { percentage of oxygen in the oxidant (\%) }
\end{aligned}
$$

The partial pressures and the Nernst voltage are determined in Block 2 in Fig. 3 as follows [21, 27]:

$$
\left\{\begin{array}{c}
P_{H 2}=\left(1-U_{f H 2}\right) x_{h} \% P_{\text {fuel }} \\
P_{O 2}=\left(1-U_{f O 2}\right) x_{h} \% P_{\text {air }} \\
P_{H_{2} O}=\left(w-2 y_{h} \% U_{f O 2}\right) P_{\text {air }} \\
E_{n}=1.229-\frac{44.43}{z F}(T-298)+\frac{R T}{z F} \ln \left(P_{H 2} P_{O 2}^{\frac{1}{2}}\right) \\
E_{n}=1.229-\frac{44.43}{z F}(T-298)+\frac{R T}{z F} \ln \left(\frac{P_{H 2} P_{O 2}^{\frac{1}{2}}}{P_{H_{2} O}}\right) \text { for }(T>373 K)
\end{array}\right.
$$

where

$P_{\mathrm{H}_{2} \mathrm{O}}=$ partial pressure of water vapor (atm).

$w=$ percentage of water vapor in the oxidant (\%). 


\section{4- Proposed Controller Design}

On top of the overall PEMFC-DC-DC-IBC model, an appropriate switching technique is developed in this section to ensure the optimal desired output in the presence of load disturbances and model uncertainties. It was illustrated that the average state space LTI representation of the converter is quite sensitive to the changes in the input voltage, output load variations, disturbances, and modelling as well as sensor uncertainties. For this reason, a PSO-based Robust Nonlinear Controller, called PSO-RNC, is designed to correct for the aforementioned drawback and to continuous and optimal set-point tracking of the desired voltage $\left(V_{\text {cref }}\right)$ by acting on the duty cycle $(u)$ of the IBC switch.

\section{1- Main results}

The controller design procedure for the DC-DC IBC includes three steps; virtual control inputs are developed during the first two steps, and the actual control input is designed in the last step.

Let us define the following variables that define the error dynamics of the system studied Eq.(4) :

$$
\left\{\begin{array}{l}
e_{1}=\int\left(V_{c r e f}-V_{c}\right) d t \\
e_{2}=V_{c r e f}-V_{c} \\
e_{3}=I_{f c_{d}}-I_{f c}
\end{array}\right.
$$

with $\dot{V}_{\text {cref }}=0$.

The derivative with respect to time of the Eq.(10) are :

$$
\left\{\begin{array}{l}
\dot{e}_{1}=e_{2} \\
\dot{e}_{2}=-\dot{V}_{c}=-\frac{1}{C} I_{f c} u+\frac{1}{R C} V_{c} \\
\dot{e}_{3}=\dot{I}_{f c_{d}}-\frac{2}{L} V_{f c}+\frac{2}{L} V_{c} u(t)
\end{array}\right.
$$

Eq. (11) presents the error dynamics and can be considered in terms of a control problem where the system to be controlled is a nonlinear system with a control input $u(t)$. As long as the control input $(u(t))$ can stabilize the nonlinear system, the error vector $e=\left[e_{1}, e_{2}, e_{3}\right]^{T}$ converges to zero as time $t \rightarrow \infty$. This implies that the trajectory of the controlled system Eq. (11) asymptotically approaches the target $\left[\int V_{c r e f}, V_{c}, I_{f c_{d}}\right]^{T}$. 
The design procedure of the controller is recursive. At the $i$ th step, the $i$ th-order subsystem is stabilized using Lyapunov function $V_{i}$ by the design of a virtual control a $\Phi_{i}$ and a control input function $u_{i}$.

Step 1. Let $z_{1}=e_{1}$, then we can obtain its derivative:

$$
\dot{z}_{1}=\dot{e}_{1}=e_{2}
$$

where $e_{2}=\Phi_{1}\left(z_{1}\right)$ is introduced as a virtual control input.

For the design of $\Phi_{1}\left(z_{1}\right)$ in order to stabilize $z_{1}$-subsystem Eq.(12), we can select the following Lyapunov function:

$$
V_{1}=\frac{1}{2} z_{1}^{2}
$$

The time derivative of $V_{1}$ is given below:

$$
\dot{V}_{1}=z_{1} \dot{z}_{1}=z_{1} \Phi_{1}\left(z_{1}\right)
$$

By introducing $\Phi_{1}\left(z_{1}\right)=-k_{1} z_{1}, k_{1}>0, \dot{V}_{1}$ is negative definite. This implies that the $z_{1}$ subsystem Eq.(12) is asymptotically stable. Since the virtual control function $\Phi_{1}\left(z_{1}\right)$ is estimative, the following error is define as :

$$
z_{2}=e_{2}-\Phi_{1}\left(z_{1}\right)
$$

Then one can obtain the following $\left(z_{1}, z_{2}\right)$-subsystem:

$$
\left\{\begin{array}{l}
\dot{z}_{1}=e_{2} \\
\dot{z}_{2}=\dot{e}_{2}-\dot{\Phi}_{1}\left(z_{1}\right)=-\frac{1}{C} I_{f c} u+\frac{1}{R C} V_{c}-\dot{\Phi}_{1}\left(z_{1}\right)
\end{array}\right.
$$

Step 2. Adding and subtracting $-k_{1} z_{1}$ to the Eq.(12), the $\left(z_{1}, z_{2}\right)$-subsystem can then be represented as follows:

$$
\left\{\begin{array}{l}
\dot{z}_{1}=e_{2}-\Phi_{1}\left(z_{1}\right)+\Phi_{1}\left(z_{1}\right)=\Phi_{1}\left(z_{1}\right)+z_{2} \\
\dot{z}_{2}=\dot{e}_{2}-\dot{\Phi}_{1}\left(z_{1}\right)=-\frac{1}{C} I_{f c} u+\frac{1}{R C} V_{c}-\dot{\Phi}_{1}\left(z_{1}\right)
\end{array}\right.
$$

In a same manner, taking $I_{f c}$ as an independent input such that a stabilizing control law $\Phi_{2}\left(z_{1}, z_{2}\right)$ can get as: 


$$
\Phi_{2}\left(z_{1}, z_{2}\right)=I_{f c_{d}}=\frac{C}{u}\left(z_{1}-\dot{\Phi}_{1}\left(z_{1}\right)+\frac{1}{R C} V_{c}+k_{2} z_{2}\right)
$$

Substitute Eq.(18) into Eq.(17) and consider a second augmented Lyapunov function candidate $V_{2}=V_{1}+\frac{1}{2} z_{2}^{2}$, then the time derivative of $V_{2}$ is:

$$
\dot{V}_{2}=-k_{1} z_{1}^{2}+z_{2} z_{1}+z_{2} \dot{z}_{2}=-k_{1} z_{1}^{2}-k_{2} z_{2}^{2} \leq 0
$$

where $k_{2}>0$. Define a new error variable as $z_{3}=e_{2}-\Phi_{2}\left(z_{1}, z_{2}\right)$. In the control point of view, it can be computed that if the error variables $z_{3}$ approaches zero, the asymptotical stability of the $\left(z_{1}, z_{2}\right)$-subsystem can be ensured. Consider Eq.(17), by adding and subtracting $-\frac{1}{C} \Phi_{2}\left(z_{1}, z_{2}\right) u$ to the subsystem $z_{2}$, then the final subsystem is define as :

$$
\begin{aligned}
& \left\{\begin{array}{l}
\dot{z}_{1}=\Phi_{1}\left(z_{1}\right)+z_{2} \\
\dot{z}_{2}=-\frac{1}{C} I_{f c} u+\frac{1}{R C} V_{c}-\dot{\Phi}_{1}\left(z_{1}\right)-\frac{1}{C} \Phi_{2}\left(z_{1}, z_{2}\right) u+\frac{1}{C} \Phi_{2}\left(z_{1}, z_{2}\right) u \\
\dot{z}_{3}=\dot{e}_{2}-\dot{\Phi}_{2}\left(z_{1}, z_{2}\right)=-\frac{2}{L} V_{f c}+\frac{2}{L} V_{c} u(t)
\end{array}\right. \\
& \left\{\begin{array}{l}
\dot{z}_{1}=\Phi_{1}\left(z_{1}\right)+z_{2} \\
\dot{z}_{2}=\frac{1}{c} z_{3} u-z_{1}-k_{2} z_{2} \\
\dot{z}_{3}=\dot{e}_{2}-\dot{\Phi}_{2}\left(z_{1}, z_{2}\right)=-\frac{2}{L} V_{f c}+\frac{2}{L} V_{c} u(t)
\end{array}\right.
\end{aligned}
$$

Step 3. we choose the third augmented Lyapunov positive definite function described as follows:

$$
V_{3}=V_{2}+\frac{1}{4} \frac{L}{C} z_{3}^{2}
$$

Using Eq. (20) and Eq.(12), $V_{3}$ can be derived as follows:

$$
\begin{gathered}
\dot{V}_{3}=-k_{1} z_{1}^{2}+z_{2} z_{1}+z_{2} \dot{z}_{2}+z_{3} \dot{z}_{3} \\
\dot{V}_{3}=-k_{1} z_{1}^{2}+z_{2}\left(z_{1}+\frac{1}{C} z_{3} u-z_{1}-k_{2} z_{2}\right)+\frac{L}{2 C} z_{3}\left(-\frac{2}{L} V_{f c}+\frac{2}{L} V_{c} u(t)\right) \\
\dot{V}_{3}=-k_{1} z_{1}^{2}-k_{2} z_{2}^{2}+\frac{1}{C} z_{3} u z_{2}+z_{3}\left(-\frac{2}{L} V_{f c}+\frac{2}{L} V_{c} u(t)\right) \\
\dot{V}_{3}=-k_{1} z_{1}^{2}-k_{2} z_{2}^{2}+\frac{L}{2 C} z_{3}\left(-\frac{2}{L} V_{f c}+\frac{2}{L} V_{c} u+\frac{2 u}{L} z_{2}\right) \\
\dot{V}_{3}=-k_{1} z_{1}^{2}-k_{2} z_{2}^{2}+\frac{L}{2 C} z_{3}\left(-\frac{2}{L} V_{f c}+\frac{2 u}{L}\left(V_{c}+z_{2}\right)\right)
\end{gathered}
$$




$$
\begin{gathered}
\dot{V}_{3}=-k_{1} z_{1}^{2}-k_{2} z_{2}^{2}+\frac{L}{2 C} z_{3}\left(-\frac{2}{L} V_{f c}+\frac{2 u}{L}\left(V_{c}+e_{2}-\Phi_{1}\left(z_{1}\right)\right)\right) \\
\dot{V}_{3}=-k_{1} z_{1}^{2}-k_{2} z_{2}^{2}+\frac{L}{2 C} z_{3}\left(-\frac{2}{L} V_{f c}+\frac{2 u}{L}\left(V_{c}+V_{c r e f}-V_{c}-\Phi_{1}\left(z_{1}\right)\right)\right) \\
\dot{V}_{3}=-k_{1} z_{1}^{2}-k_{2} z_{2}^{2}+\frac{L}{2 C} z_{3}\left(-\frac{2}{L} V_{f c}+\frac{2 u}{L}\left(V_{c r e f}-k_{1} e_{1}\right)\right)
\end{gathered}
$$

The objective is to guarantee that $\dot{V}_{3}$, given by Eq.(23), is non-positive to satisfy the Lyapunov stability condition. So, the corresponding designed control law (u), which forces the system output to track the reference set point, is given by:

$$
\begin{array}{r}
u=\frac{L}{2\left(V_{c r e f}-k_{1} e_{1}\right)}\left(-\dot{I}_{f c_{d}}+\frac{2}{L} V_{f c}-k_{3} e_{3}\right) \\
u=\frac{L}{2\left(V_{c r e f}-e_{2}\right)}\left(-\dot{I}_{f c_{d}}+\frac{2}{L} V_{f c}-k_{3} e_{3}\right)
\end{array}
$$

To ensure that $\dot{V}_{3}$ is negative definite:

$$
\dot{V}_{3}=-k_{1} z_{1}^{2}-k_{2} z_{2}^{2}-\frac{L}{2 C} k_{3} z_{3}^{2}
$$

where $k_{1}, k_{2}$ and $k_{3}$ are positive constants to be heuristically determined using the PSO technique as presented in Section 5.

\subsection{PI Controller Design}

A second proposed solution consists of a PSO-optimized PI Controller, named PSO-PIC, designed to regulate the IBC output. This design is structured as follows [34]:

$$
u(t)=1-U_{p i}
$$

with

$$
U_{p i}=K_{p}\left(V_{\text {cref }}-V_{c}\right)+K_{i} \int\left(V_{\text {cref }}-V_{c}\right) d t
$$

This controller is implemented for comparison purposes. Its parameters $K_{p}$ and $K_{i}$ of the $\mathrm{PI}$ controller of Eq. (27) are heuristically tuned using the PSO technique as covered in the following section. 


\section{5- PSO-Based Controllers' Parameters}

Particle Swarm Optimization is a stochastic population-based optimization technique inspired by the behaviour of birds and fish swarms. The PSO algorithm was developed by Eberhart and Kennedy in 1995 [1]. A candidate solution in a PSO optimization problem mimics a bird in the search space, which is called a particle. The PSO algorithm is used to determine possible solutions by moving particles randomly in accordance with some designed rules [2-5]. A general flowchart of PSO algorithm is given in Fig. 4.

There are two key factors that dominate the performance of standard PSO algorithm. The particle velocity and the particle position update. The $(t+1)^{t h}$ velocity is obtained as follows [28-30]:

$$
V_{j}(t+1)=w * V_{j}(t)+C_{1} r_{1}\left(p_{j}-X_{j}(t)\right)+C_{2} r_{2}\left(p_{g}-X_{j}(t)\right)
$$

where $t$ represents the iteration number; $j$ is the particle number; the vector $p_{j}$ is the individual best solution of particle $j$ at a given stage; the vector $p_{g}$ is the global best solution calculated from all the particles at $t$; the constants $C_{1}$ and $C_{2}$ are the acceleration parameters; the vectors $r_{1}$ and $r_{2}$ are random numbers uniformly distributed between 0 and 1.

On the other hand, the particle position is updated, through its current velocity, towards the optimal solution as follows $[30,31,35]$ :

$$
X_{j}(t+1)=X_{j}(t)+V_{j}(t+1)
$$

Using this methodology, the PSO technique is employed to determine the optimum parameters of each of the previously designed controllers. The Integral Absolute value of the Error objective function is used in this work based on the input-output error, the maximum value of each computation process at a given stage is used as the update value. 


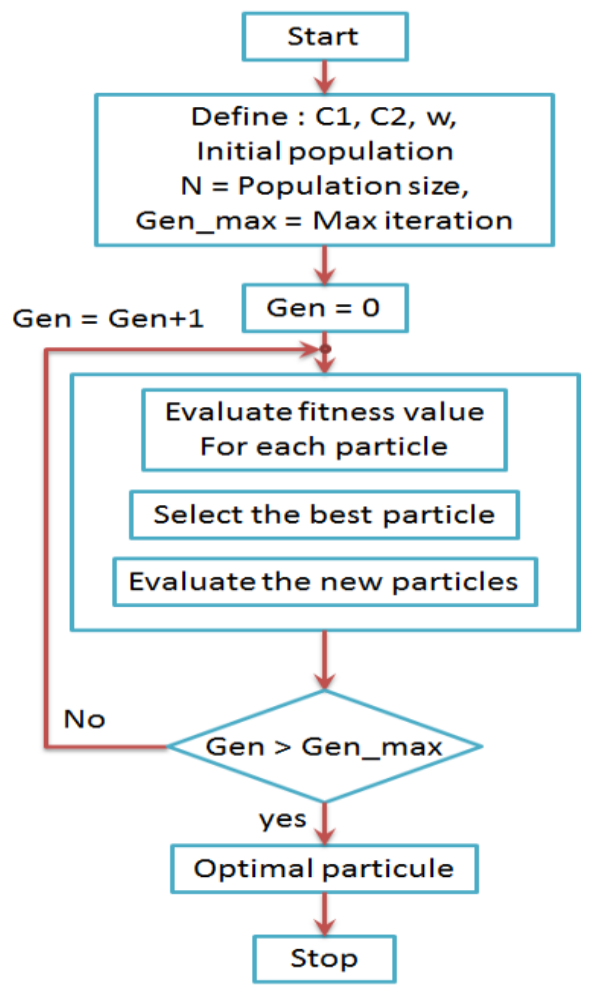

Fig. 4 Flowchart for PSO-based tuning controller parameters.

The main objective function is given as follows $[10,11]$ :

$$
I A E=\int_{0}^{\infty}|e(t)| d t=\int_{0}^{\infty}\left|e_{2}(t)\right| d t
$$

where $e(t)$ is the instantaneous voltage tracking error as defined in Eq. (10).

Notice that Eq.(30) also represents the performance index of each design, namely the proposed PSO-optimized nonlinear robust controller (PSO-NRC) and PSO-based PI controller (PSO-PIC). The different steps used for tuning these controllers are illustrated in Fig. 5. 


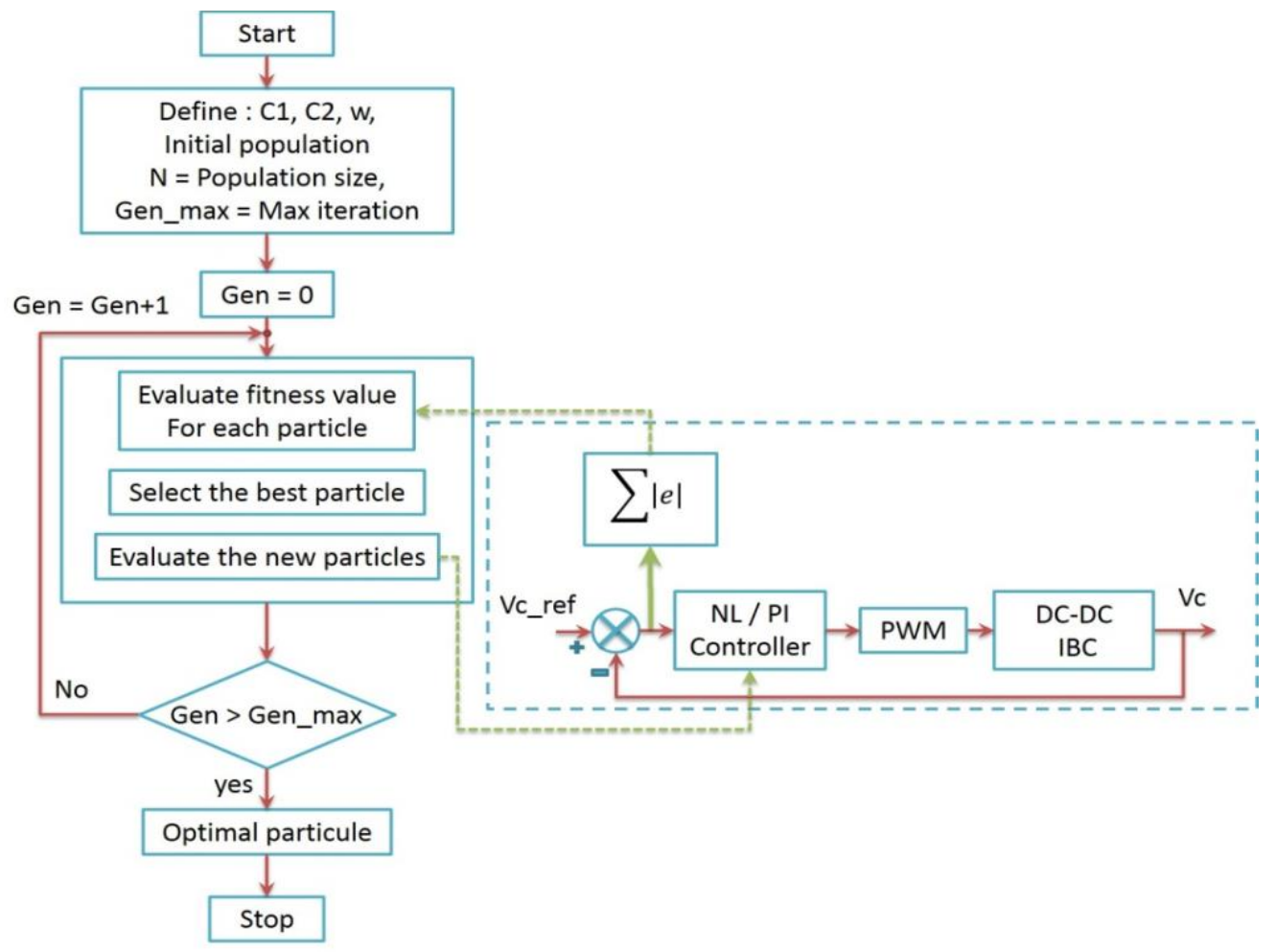

Fig. 5 Proposed Block diagram of PSO-based control design.

\section{6- Results and Discussion}

The overall system structure combining the PEMFC, the IBC, and different controllers as well as their parameters are detailed in this section. This is followed by evaluation and comparisons of the overall system performance for each controller design. The key parameters of the DC-DC IBC and the PEMFC are respectively listed in Table I and Table II.

Table I. Parameters of DC-DC interleaved boost converter.

\begin{tabular}{lc}
\hline \multicolumn{1}{c}{ Parameter } & Value \\
\hline $\boldsymbol{L}$ & $5000 \mu \mathrm{H}$ \\
$\boldsymbol{R}_{\boldsymbol{L}}$ & $0.15 \Omega$ \\
$\boldsymbol{C}$ & $1000 \mu F$ \\
$\boldsymbol{R} \boldsymbol{c}$ & $1000 \Omega$ \\
$\boldsymbol{R}$ & $5 \Omega$ \\
\hline
\end{tabular}

where $R_{c}$ is the parasitic resistance of the capacitor and $R_{L}$ is the inductor resistance. 
Table II. Operative parameters of a $6 \mathrm{KW}-48 \mathrm{~V}$ fuel cell stack.

\begin{tabular}{lcl}
\hline \hline \multicolumn{1}{c}{ Parameter } & Value & \multicolumn{1}{c}{ Components name } \\
\hline \hline $\mathrm{FC}_{\text {Eoc }}$ & 65 & Voltage at 0 A (V) \\
$F C_{V 1}$ & 63 & Nominal operating Current (A) \\
$F C_{\text {Inom }}$ & 133.3 & Voltage at 1 A (V) \\
$F C_{\text {Vnom }}$ & 45 & Nominal operating Voltage (V) \\
$F C_{\text {Imax }}$ & 225 & Maximum operating Current (A) \\
$F C_{\text {Vmin }}$ & 37 & Minimum operating Voltage (V) \\
$F C_{N}$ & 65 & Number of cells in series \\
$F C_{\text {Tnom }}$ & 65 & Operating temperature ( $\mathrm{C})$ \\
$F C_{\text {Nnom }}$ & 55 & Nominal stack efficiency (\%) \\
$F C_{\text {Vair }}$ & 300 & Nominal air flow rate (L/min) \\
$F C_{\text {fuel }}$ & 1.5 & Nominal supply pressure Fuel (bar) \\
$F C_{\text {Pair }}$ & 1 & Nominal supply pressure Air (bar) \\
$F C_{\text {Ph2 }}$ & 99.95 & Nominal composition of H2 (\%) \\
$F C_{\text {Po2 }}$ & 21 & Nominal composition of O2 (\%) \\
$F C_{\text {Ph2o }}$ & 1 & Nominal composition of H2O (Air) (\%) \\
$R_{\text {ohm }}$ & 0.09604 & \\
$E$ & 57.91 & \\
\hline \hline
\end{tabular}

The PSO-optimized parameters for the PSO-NRC and the PSO-PIC designs and their respective search ranges are listed in Table III and IV, respectively.

Table III. Selection of parameters used for PSO-based tuning of the proposed and the PI controllers.

\begin{tabular}{lcc}
\hline \hline \multirow{2}{*}{ PSO Parameters } & \multicolumn{2}{c}{ Value } \\
\cline { 2 - 3 } & PSO- PIC & PSO-NRC (proposed controller) \\
\hline \hline $\boldsymbol{C}_{\mathbf{1}}$ & 1 & 1 \\
$\boldsymbol{C}_{\mathbf{2}}$ & 3 & 3 \\
$\boldsymbol{w}$ & 0.8 & 0.8 \\
Population size & 100 & 100 \\
Maximum iteration & 20 & $\mathbf{5}$ \\
\hline \hline
\end{tabular}

Using the constructed PEMFC-DC-DC-IBC model, the gains $k_{1}, k_{2}$ and $k_{3}$ of the proposed PSO-NRC design and $K_{p}$ and $K_{i}$ gains of the $\mathrm{PI}$ controller are heuristically tuned by minimizing the optimization problem given by Eq (28). This procedure is shown in Fig. 5, the optimum final gains are listed in Table V. 
Table IV. Search range of the controller parameters

\begin{tabular}{lcc}
\hline \multirow{2}{*}{ Controller parameters } & \multicolumn{2}{c}{ Search range } \\
\cline { 2 - 3 } & Min & Max \\
\hline \hline$k_{1}$ & 30 & 40 \\
$k_{2}$ & 15 & 20 \\
$k_{3}$ & 5 & 15 \\
$K_{p}$ & 0 & 0.1 \\
$K_{i}$ & 1 & 15 \\
\hline \hline
\end{tabular}

Table V. Optimal parameters of both controllers.

\begin{tabular}{llll}
\hline \hline PSO- PIC & $K_{p}=0.0077$, & $K_{i}=1.28$ & \\
\hline \hline PSO-NRC & $k_{1}=30.4131$, & $k_{2}=15.4350$, & $k_{3}=9.8251$ \\
\hline \hline
\end{tabular}

In order to verify the PEMFC-DC-DC-IBC performance using each of the designed controllers and check which one ensures the best tracking performance, the comparisons between the proposed and the PSO-based PI controllers are based on the dynamic output characteristics. Simulations are performed for three different cases, two different numerical simulation scenarios include output voltage variation, and a third scenario is simulated under load variation. The platform that was developed to simulate the system is depicted in Fig. 6. 


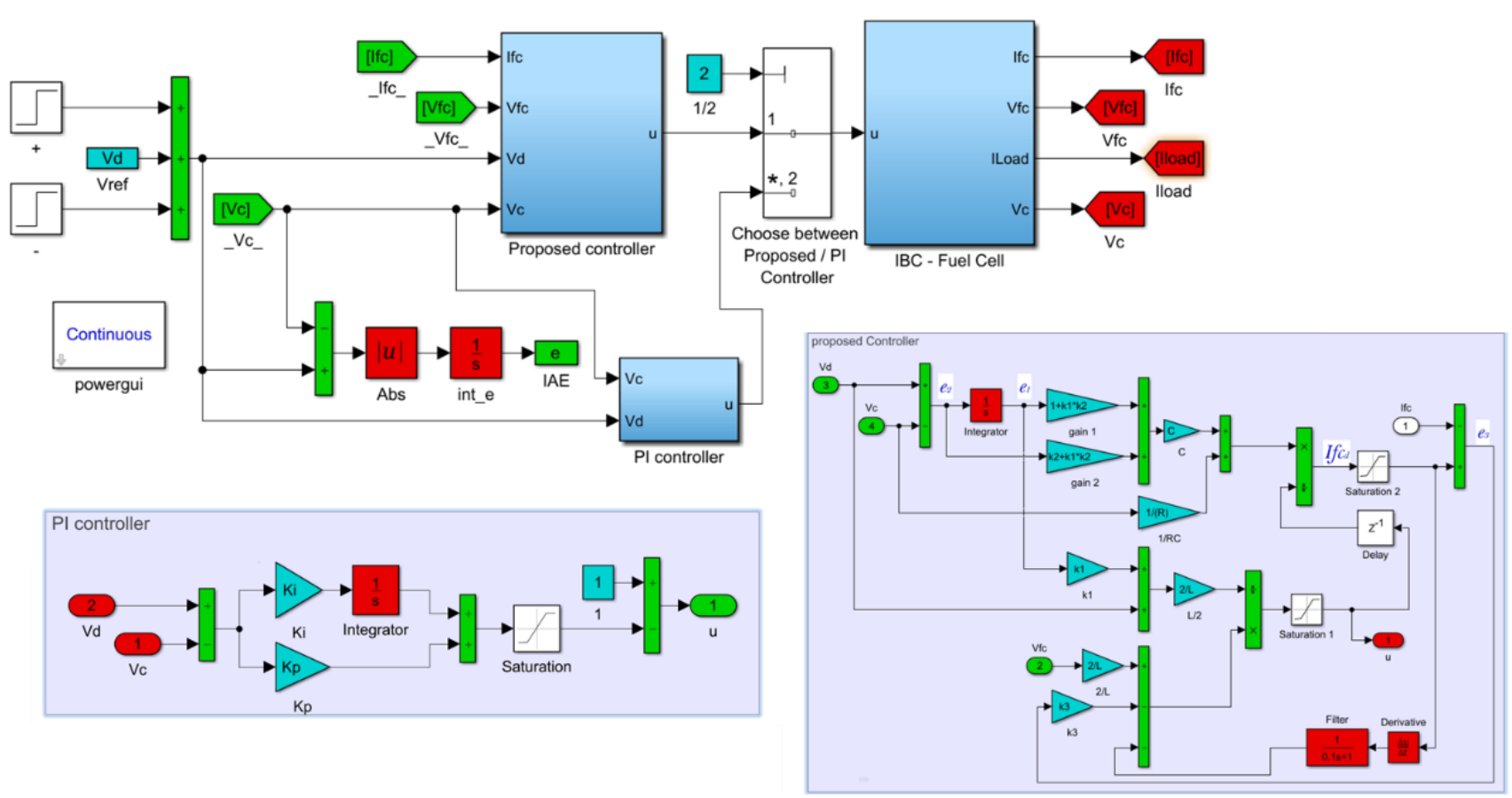

Fig. 6. Proposed system/ control strategies.

\section{6-1. Standard Test}

A comparison between the two converters is considered in this scenario. Fig. 7 and 8 represent respectively voltages and currents response and steady-state variations using the interleaved boost converter versus the classical boost converter. Those results confirm the superiority of the $\mathrm{IBC}$ to reduce ripples compared to the classical boost converter. In addition to its robustness to input voltage and load variations, the proposed PSO-RNC designed for a PEFMC-DC-DC-IBC is highly effective in regulating the output voltage to optimally track a varying set-point. 


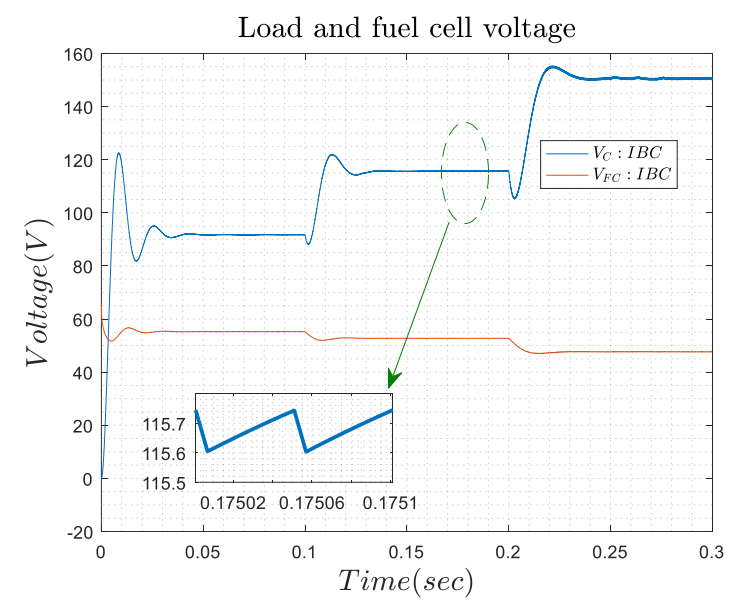

(a) Using interleaved boost converter

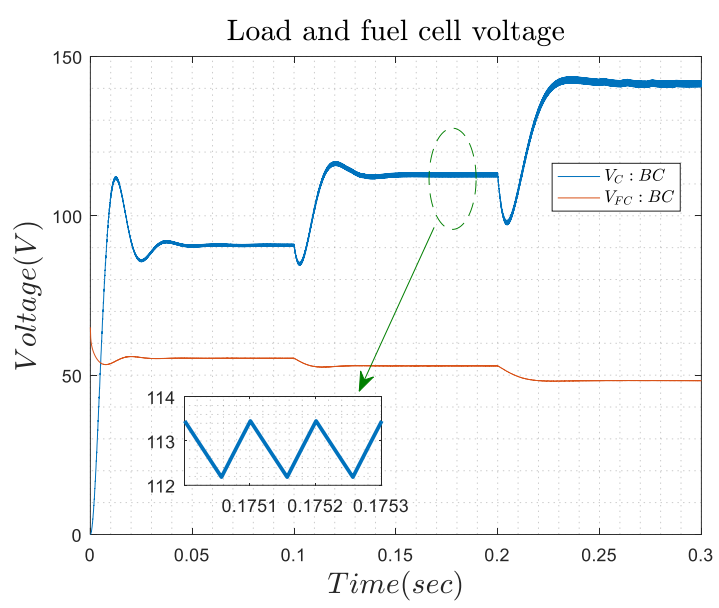

(b) Using the classical boost converter

Fig 7. Variations of load and fuel cell voltages using both converters (a) and (b).

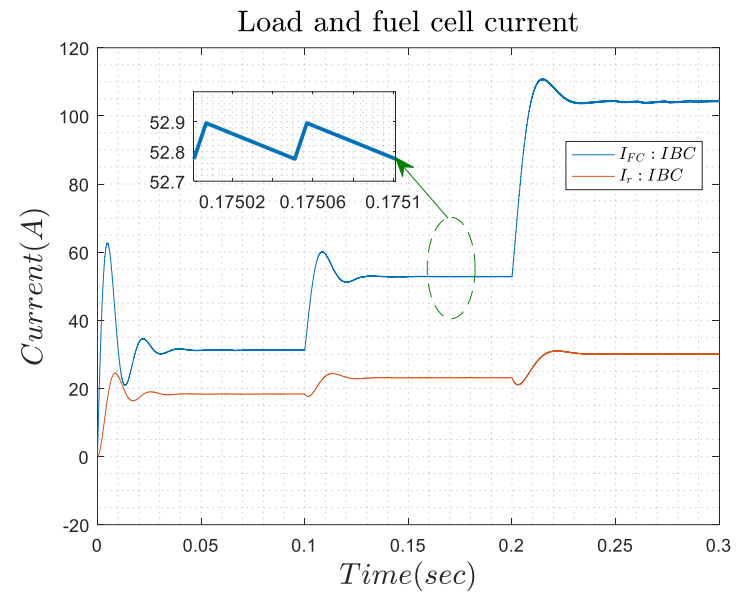

(a) Using interleaved boost converter

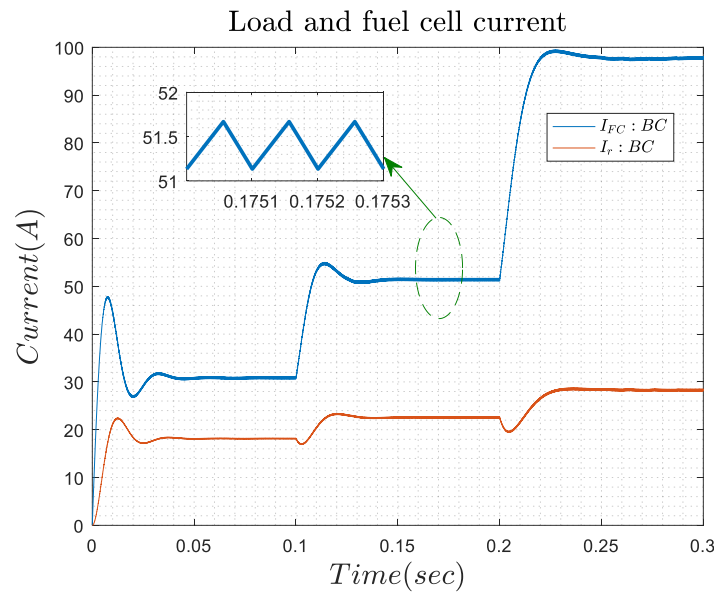

(b) Using the classical boost converter

Fig 8. Variations of load and fuel cell currents using both converters (a) and (b).

\section{6-2. First Scenario: Variation in the Input Voltage $\left(V_{\text {cref }}\right)$ Set-Point}

In this scenario, the system studied is subject to $5 \%$ decrease in the reference voltage $V_{\text {cref }}$ at $t=$ $0.1 \mathrm{~s}$, and $5 \%$ increase in $V_{\text {cref }}$ at $t=0.15 \mathrm{~s}$. Fig. 9 demonstrates the performance of each of the two controllers, and it can be observed that the proposed controller can rapidly regulate the output voltage of the IBC. In addition, the closed-loop system using the proposed controller settles to the final value with a shorter Rise time compared to the PSO-PIC as demonstrated in Table VI. 
Table VI. Rise time in seconds

\begin{tabular}{lccc}
\hline \hline Time $(\mathrm{s})$ & {$\left[\begin{array}{lll}0.0 & 0.1\end{array}\right]$} & {$\left[\begin{array}{lll}0.1 & 0.15\end{array}\right]$} & {$\left[\begin{array}{lll}0.15 & 0.25\end{array}\right]$} \\
\hline \hline PSO- PIC & 0.0098 & 0.0100 & 0.0104 \\
PSO-RNC & $\mathbf{0 . 0 0 5 9}$ & $\mathbf{0 . 0 0 5 7}$ & $\mathbf{0 . 0 0 6 3}$ \\
\hline \hline
\end{tabular}

Furthermore, for statistic comparison, the IAE criterion is employed for both methods and the corresponding results are summarized in Table VII. The results obtained confirm that the proposed PSO-NRC leads to a more reliable performance in terms of output regulation of IBC (load voltage) compared to the PSO-PIC according to the IAE criterion.

Table VII. Performance index of the proposed and PSO- PI controllers.

\begin{tabular}{cccc}
\hline \hline \multicolumn{4}{c}{$I A E=\int_{0}^{\infty}|e(t)| d t=\int_{0}^{\infty}\left|e_{2}(t)\right| d t$} \\
\hline \hline Time (s) & {$\left[\begin{array}{llll}0.0 & 0.1\end{array}\right]$} & {$\left[\begin{array}{lll}0.1 & 0.15\end{array}\right]$} & {$\left[\begin{array}{ll}0.15 & 0.25\end{array}\right]$} \\
\hline \hline PSO-PIC & 0.0566 & 0.0468 & 0.1044 \\
PSO-RNC & $\mathbf{0 . 0 4 0 8}$ & $\mathbf{0 . 0 3 0 6}$ & $\mathbf{0 . 0 7 9 6}$ \\
\hline \hline
\end{tabular}

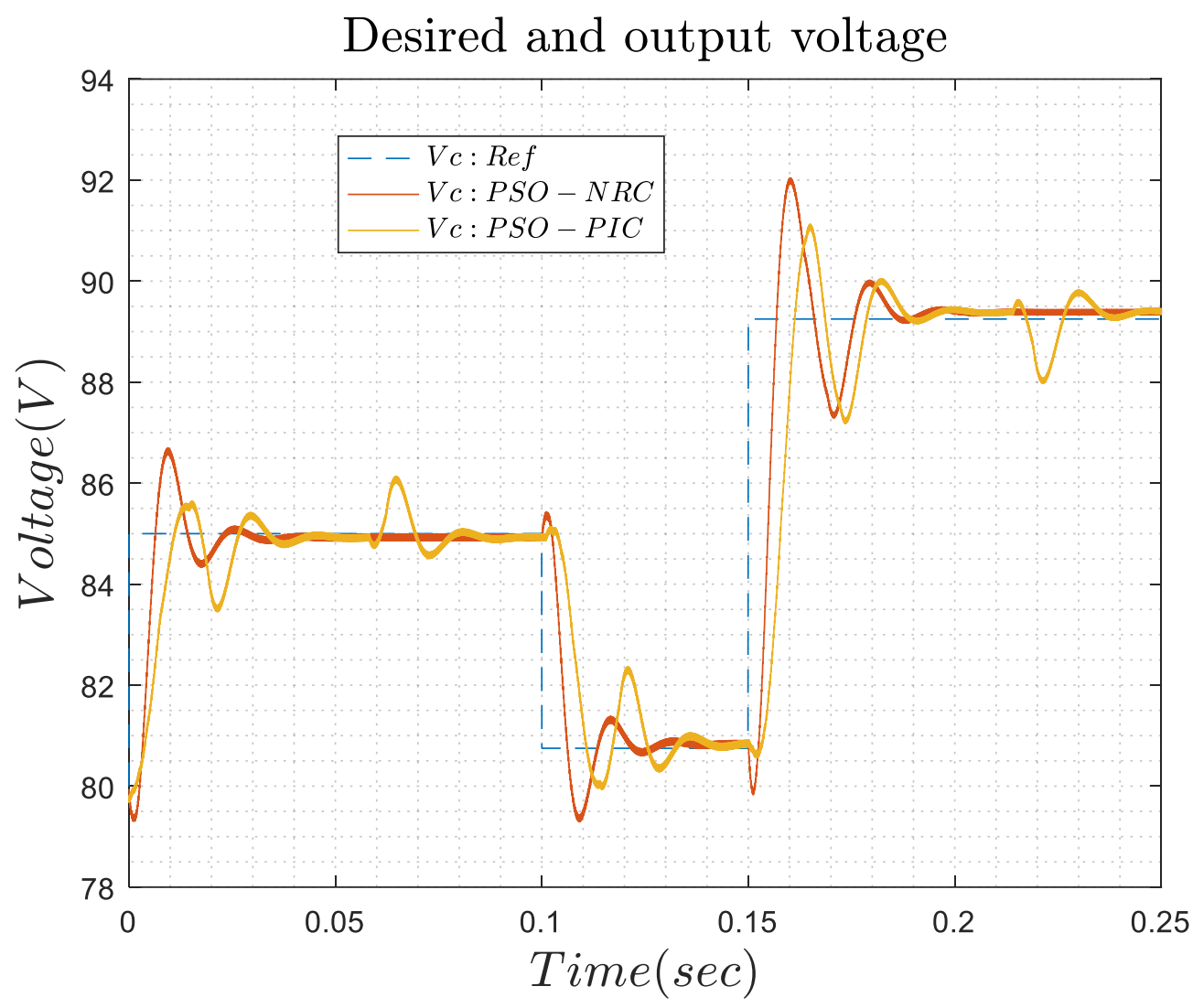


Fig 9. Regulated output voltage of the IBC (Voltage tracking response).

The corresponding load, fuel cell currents and fuel cell voltage are respectively shown in Figs. 10 and 11 . These figures demonstrate how the proposed control method greatly reduces the ripples of the load voltage as well as the fuel cell currents and voltage in the presence of variation of the load voltage.

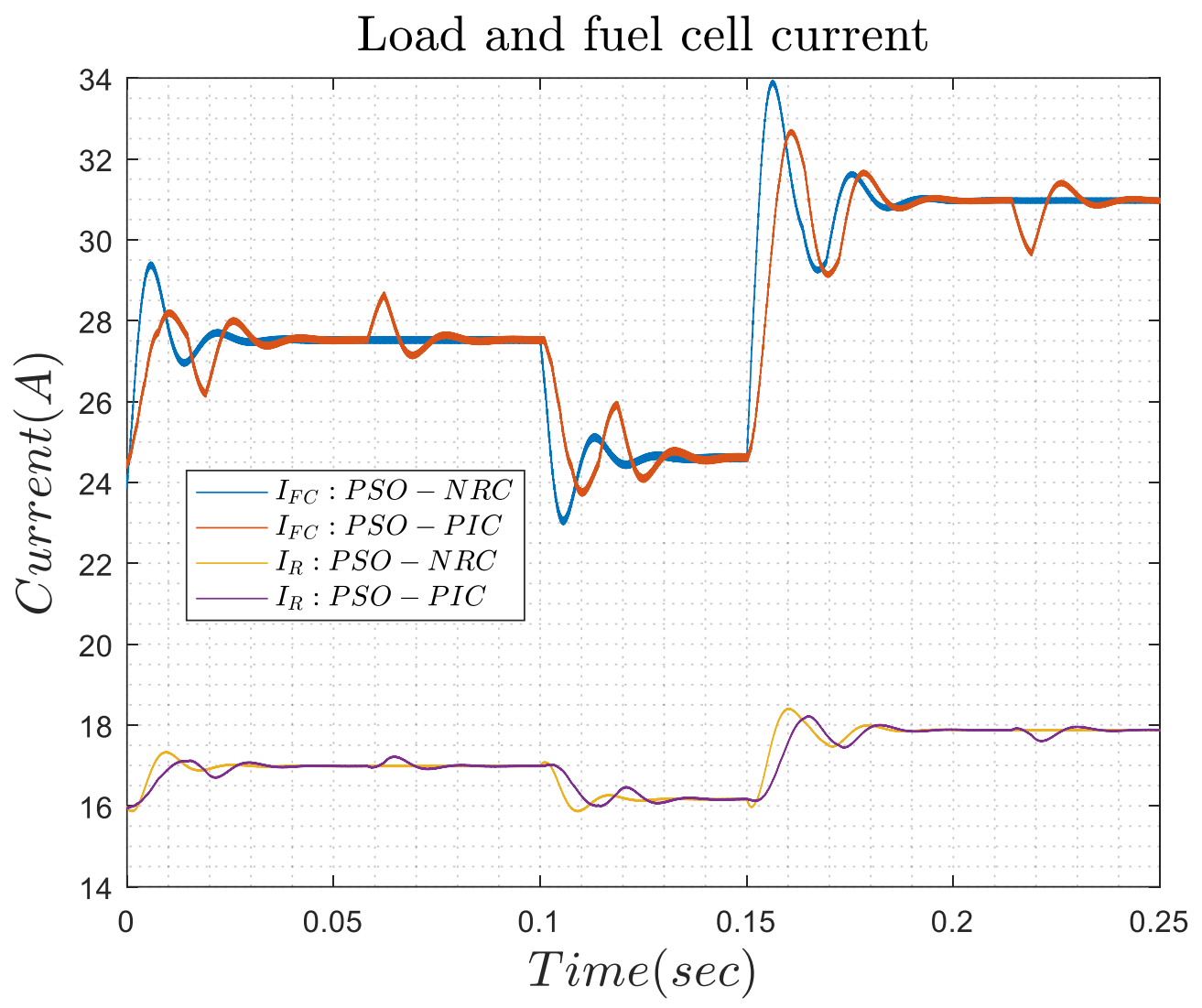

Fig 10. Fuel cell and load currents response to input voltage variation. 


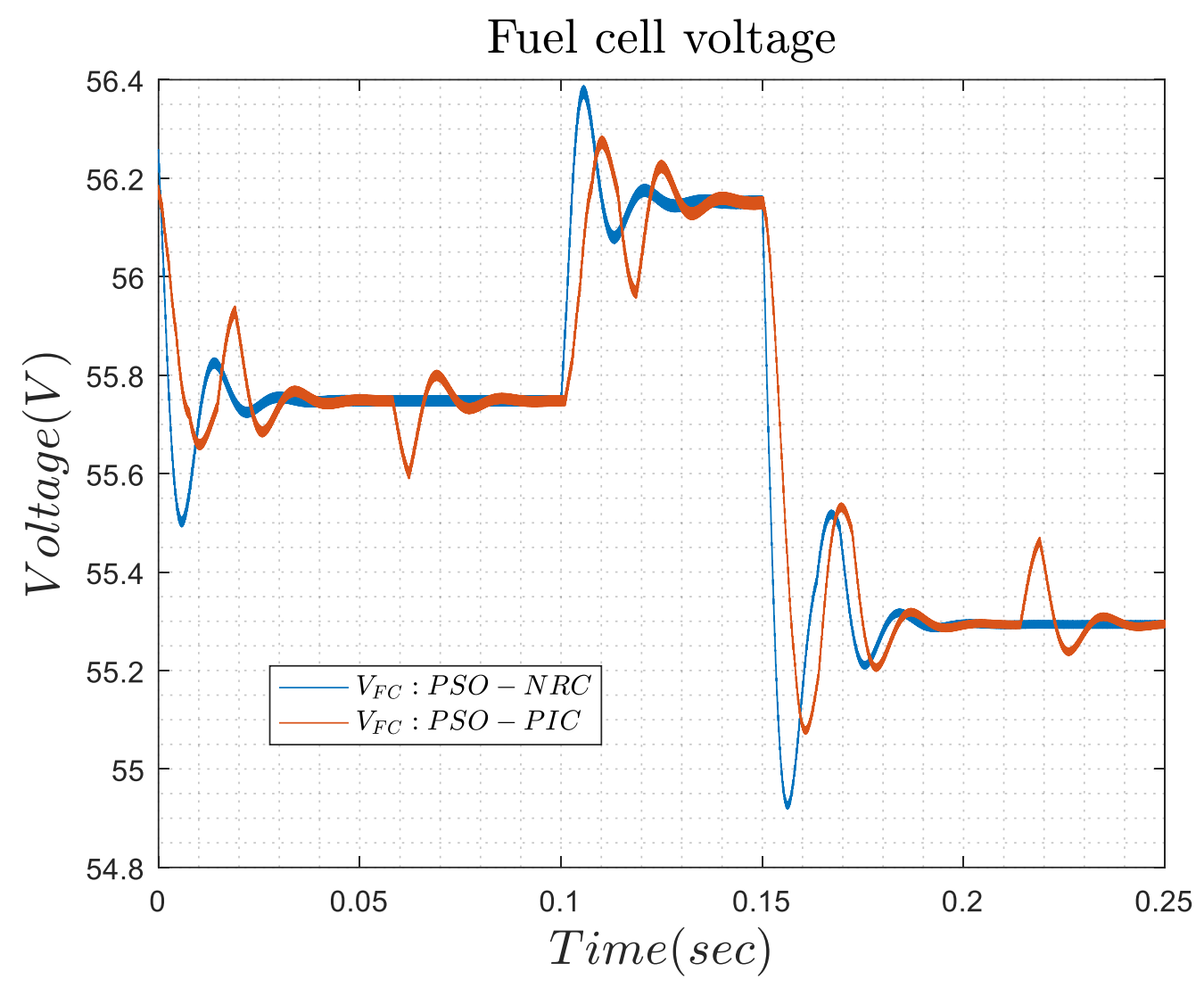

Fig 11. Fuel Cell voltage under input voltage variation.

6-3. Second Scenario: Load Variation of $-20 \%$ introduced at $t=0.05 \mathrm{~s}$

Results of this scenario are summarized in Figs. $12-14$ showing the response of the regulated output voltage of the IB converter, fuel cell and load currents, and the fuel cell voltage after a $20 \%$ variation in load at $t=0.05 \mathrm{~s}$. These responses illustrate the capabilities of the closed loop system using the proposed controller to withstand large and abrupt load variations and reach the reference voltage within a settling time of $0.01 \mathrm{~s}$. The PSO-NRC also keeps the tracking of the output voltage with a smaller overshoot ( 8.83 instead of 9.01 for PI controller) and ( 0.97 instead of 5.31 for PI controller) when the system is subject to increase or decrease in load current. These observations are summarized in Table VIII. 


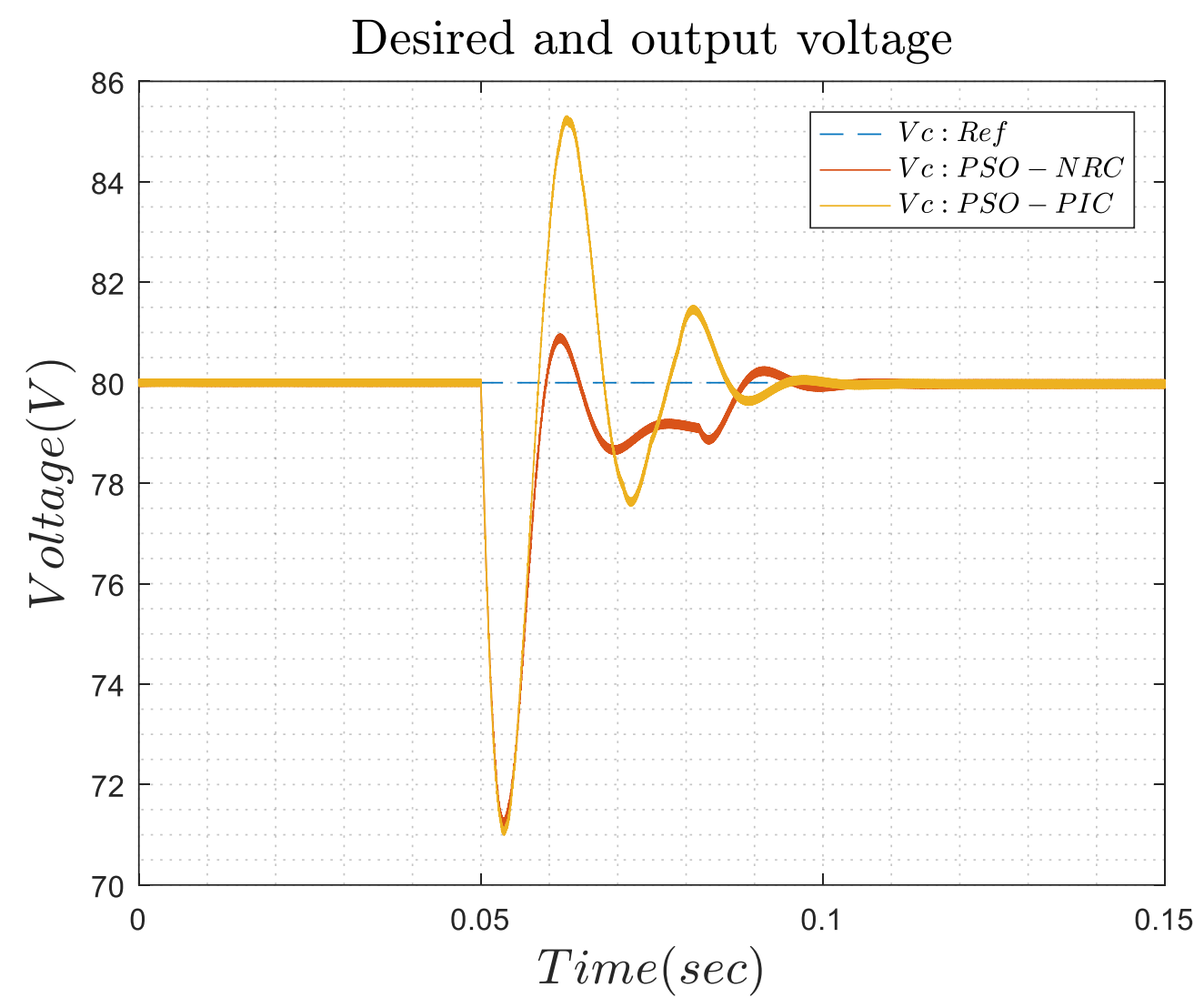

Fig. 12. Regulated output voltage of the IB converter during load variation.

Table VIII. Overshoot during second scenario

First overshoot Second overshoot

\begin{tabular}{lll}
\hline \hline PSO- PIC & 9.01 & 5.31 \\
PSO-NRC & $\mathbf{8 . 8 3}$ & $\mathbf{0 . 9 7}$ \\
\hline \hline
\end{tabular}




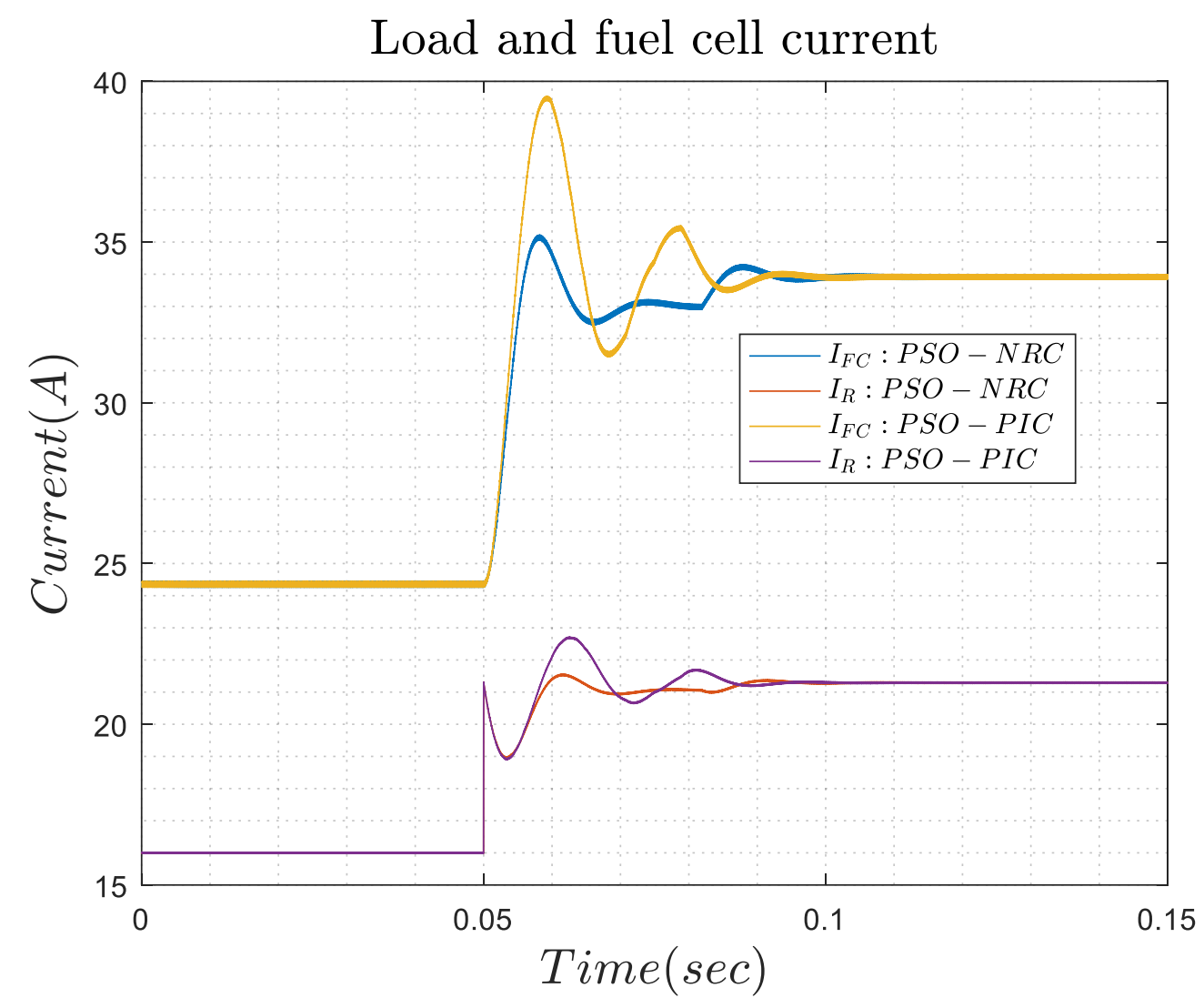

Fig 13. Fuel cell and load currents response to load variation.

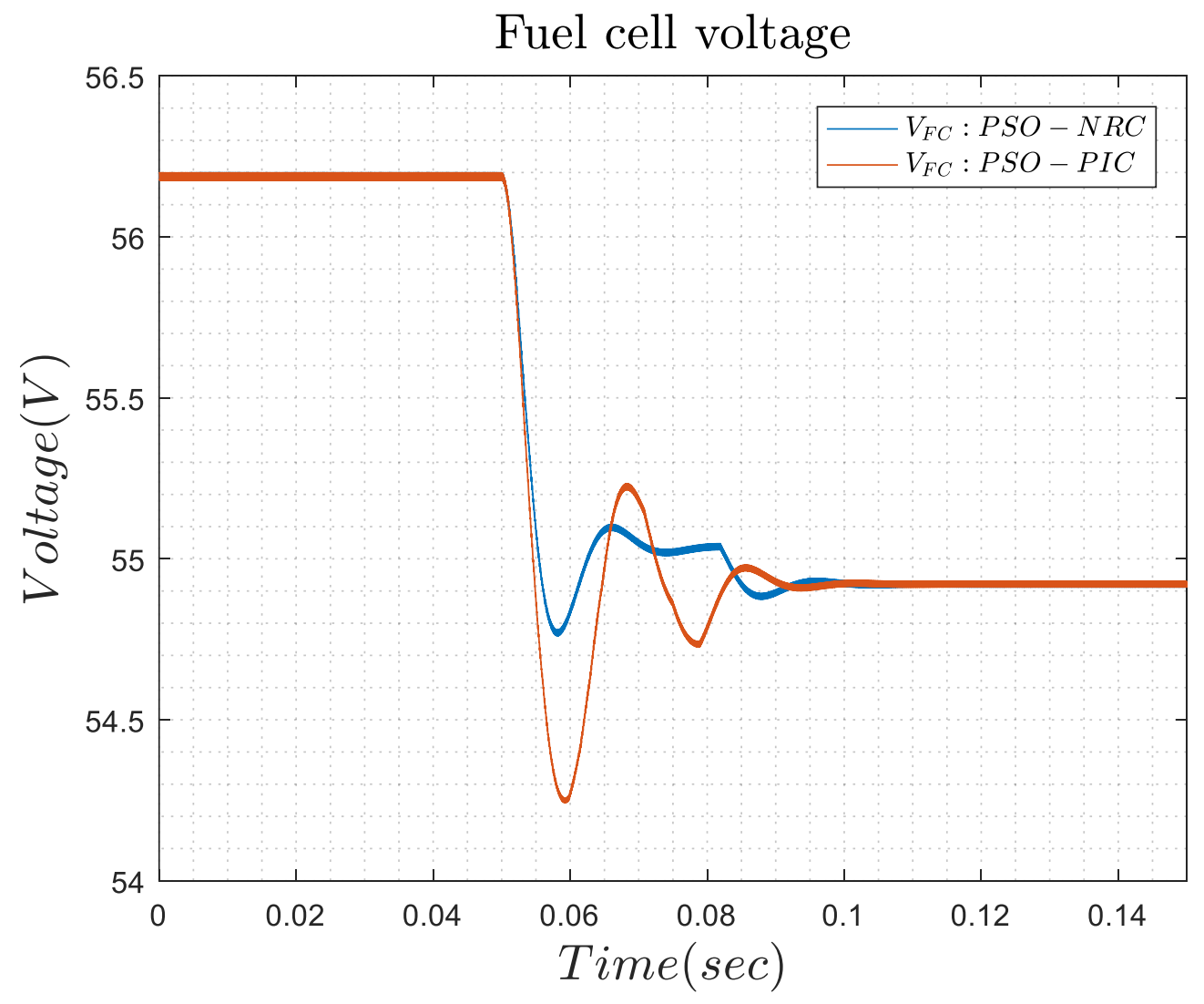


Fig 14. Fuel Cell voltage during load variation.

Consequently, in the presence of parameter uncertainties and load variations, one can see that the proposed controller is capable to achieve a robust voltage regulation performance and a smooth tracking of a varying set-point.

\section{Conclusion}

This work considered the important problem of the output voltage regulation of a PEMFC-fed DCDC interleaved boost converter in presence of model uncertainties and abrupt large variations in the input voltage as well as the load. A complete representative model is first developed for the fuel cell and the DC-DC IBC system. The control problem was formulated using Lyapunov stability theorem and the controller's parameters were tuned using PSO algorithm in order to get a good tracking of the desired output. It was illustrated that the proposed controller is capable to ensure smooth regulation of the IBC output voltage under extreme cases. Robustness was verified through the tracking error against uncertainties in the parameters of the model and sudden variations. Furthermore, simulations and comparisons of results across various scenarios reflect the improved performance achieved by the PSO-RNC compared to the PSO-PIC in terms transient behaviour and minimum ripples during steady state. The constructed PEMFC-DC-DC-IBC model, the proposed regulation structure, and the control design will be extended in future works to indirect controllers and fault tolerant control as a response to involuntary faults and system mismatches based on references [36-38].

\section{Conflict of interest}

The authors declare that they have no conflict of interest.

\section{References}

[1]. Bankupalli, P. T., Ghosh, S., Kumar, L., \& Samanta, S. (2018). Fractional order modeling and two loop control of PEM fuel cell for voltage regulation considering both source and load perturbations. International Journal of Hydrogen Energy, 43(12), 6294-6309.

[2]. Grötsch, M., Mangold, M., \& Kienle, A. (2009). Analysis of the coupling behavior of PEM fuel cells and DC-DC converters. Energies, 2(1), 71-96.

[3]. Reddy, K. J., \& Natarajan, S. (2018). Energy sources and multi-input DC-DC converters used in hybrid electric vehicle applications-A review. International Journal of Hydrogen Energy 
[4]. Li, Q., Chen, W., Wang, Y., Liu, S., \& Jia, J. (2011). Parameter identification for PEM fuel-cell mechanism model based on effective informed adaptive particle swarm optimization. IEEE Transactions on Industrial Electronics, 58(6), 2410-2419.

[5]. Bendoukha, S., Abdelmalek, S., \& Abdelmalek, S. (2018). A new combined actuator fault estimation and accommodation for linear parameter varying system subject to simultaneous and multiple faults: an LMIs approach. Soft Computing, 1-14.

[6]. Emmanuel Ogungbemi, Oluwatosin ljaodola, F.N. Khatib, Tabbi Wilberforce, Zaki El Hassan, James Thompson, Mohamad Ramadan, A.G. Olabi, FUEL CELL MEMBRANES - PROS AND CONS, Energy (2019), doi: 10.1016/j.energy.2019.01.034.

[7]. İnci, M., \& Türksoy, Ö. (2019). Review of fuel cells to grid interface: Configurations, technical challenges and trends. Journal of Cleaner Production, 213, 1353-1370.

[8]. Hossain, M. Z., \& Rahim, N. A. (2018). Recent progress and development on power DC-DC converter topology, control, design and applications: A review. Renewable and Sustainable Energy Reviews, 81, 205-230.

[9]. Guilbert, D., Collura, S. M., \& Scipioni, A. (2017). DC/DC converter topologies for electrolyzers: State-of-the-art and remaining key issues. International Journal of Hydrogen Energy, 42(38), 23966-23985.

[10]. Dali, A., Abdelmalek, S., \& Bettayeb, M. (2018, October). A New Combined Observer-State Feedback (COSF) Controller of PWM Buck Converter. In 2018 International Conference on Electrical Sciences and Technologies in Maghreb (CISTEM) (pp. 1-6). IEEE.

[11]. Abdelmalek, S., Dali, A., \& Bettayeb, M. (2018, October). An Improved Observer-based Integral State Feedback (OISF) Control Strategy of Flyback Converter for Photovoltaic Systems. In 2018 International Conference on Electrical Sciences and Technologies in Maghreb (CISTEM) (pp. 1-6). IEEE.

[12]. Choe, S. Y., Lee, J. G., Ahn, J. W., \& Baek, S. H. (2007). Integrated modeling and control of a PEM fuel cell power system with a PWM DC/DC converter. Journal of Power Sources, 164(2), 614-623.

[13]. Wang, C. M., Lin, C. H., Hsu, S. Y., Lu, C. M., \& Li, J. C. (2014). Analysis, design and performance of a zero-currentswitching pulse-width-modulation interleaved boost dc/dc converter. IET Power Electronics, 7(9), 2437-2445.

[14]. Somkun, S., Sirisamphanwong, C., \& Sukchai, S. (2015). A DSP-based interleaved boost DC-DC converter for fuel cell applications. international journal of hydrogen energy, 40(19), 6391-6404.

[15]. Kolli, A., Gaillard, A., De Bernardinis, A., Bethoux, O., Hissel, D., \& Khatir, Z. (2015). A review on DC/DC converter architectures for power fuel cell applications. Energy Conversion and Management, 105, 716-730.

[16]. Su, J. T., Liu, D. M., Liu, C. W., \& Hung, C. W. (2009, November). An adaptive control method for two-phase DC/DC converter. In 2009 International Conference on Power Electronics and Drive Systems (PEDS) (pp. 288-293). IEEE.

[17]. Ramakumar, R., \& Chiradeja, P. (2004, July). Distributed generation and renewable energy systems. In IECEC'02. 2002 37th Intersociety Energy Conversion Engineering Conference, 2002. (pp. 716-724). IEEE.

[18]. Kirubakaran, A., Jain, S., \& Nema, R. K. (2009). The PEM fuel cell system with DC/DC boost converter: design, modeling and simulation. International Journal of Recent Trends in Engineering, 1(3), 157.

[19]. Somkun, S., Sirisamphanwong, C., \& Sukchai, S. (2015). A DSP-based interleaved boost DC-DC converter for fuel cell applications. international journal of hydrogen energy, 40(19), 6391-6404.

[20]. Abbaspour, A., Khalilnejad, A., \& Chen, Z. (2016). Robust adaptive neural network control for PEM fuel cell. International Journal of Hydrogen Energy, 41(44), 20385-20395.

[21]. Barhoumi, E., Ben Belgacem, I., Khiareddine, A., Zghaibeh, M., \& Tlili, I. (2018). A Neural Network-Based Four Phases Interleaved Boost Converter for Fuel Cell System Applications. Energies, 11(12), 3423.

[22]. Romero, A., Martínez-Salamero, L., Valderrama, H., Pallás, O., \& Alarcón, E. (1998, May). General purpose slidingmode controller for bidirectional switching converters. In ISCAS'98. Proceedings of the 1998 IEEE International Symposium on Circuits and Systems (Cat. No. 98CH36187) (Vol. 6, pp. 466-469). IEEE.

[23]. Wang, W. Y., Ding, Y. H., Ke, X., \& Ma, X. (2017, December). Sliding mode control of direct coupled interleaved boost converter for fuel cell. In IOP Conference Series: Earth and Environmental Science (Vol. 100, No. 1, p. 012170). IOP Publishing.

[24]. Navarro-López, E. M., Cortés, D., \& Castro, C. (2009). Design of practical sliding-mode controllers with constant switching frequency for power converters. Electric Power Systems Research, 79(5), 796-802. 
[25]. Fernandes, D., Almeida, R., Guedes, T., Sguarezi Filho, A. J., \& Costa, F. F. (2017). State feedback control for DCphotovoltaic systems. Electric Power Systems Research, 143, 794-801.

[26]. Habib, M., Khoucha, F., \& Harrag, A. (2017). GA-based robust LQR controller for interleaved boost DC-DC converter improving fuel cell voltage regulation. Electric Power Systems Research, 152, 438-456.

[27]. Tremblay, O., \& Dessaint, L. A. (2009, September). A generic fuel cell model for the simulation of fuel cell vehicles. In 2009 IEEE Vehicle Power and Propulsion Conference (pp. 1722-1729). IEEE.

[28]. Dali, A., Bouharchouche, A., \& Diaf, S. (2015, May). Parameter identification of photovoltaic cell/module using genetic algorithm (GA) and particle swarm optimization (PSO). In 2015 3rd International Conference on Control, Engineering \& Information Technology (CEIT) (pp. 1-6). IEEE.

[29]. Rezazi, S., Hanini, S., Si-Moussa, C., \& Abdelmalek, S. (2016). Modeling and optimization of the operating conditions of marrubium vulgare I. essential oil extraction process: Kinetic parameters estimation through genetic algorithms. Journal of Essential Oil Bearing Plants, 19(4), 843-853.

[30]. Eberhart, R., \& Kennedy, J. (1995, October). A new optimizer using particle swarm theory. In MHS'95. Proceedings of the Sixth International Symposium on Micro Machine and Human Science(pp. 39-43). IEEE.

[31]. Sedraoui, M., Abdelmalek, S., \& Gherbi, S. (2011). Multivariable generalized predictive control using an improved particle swarm optimization algorithm. Informatica, 35(3).

[32]. Komathi, C., \& Gopinath, U. M. (2018). Analysis and design of genetic algorithm-based cascade control strategy for improving the dynamic performance of interleaved DC-DC SEPIC PFC converter. Neural Computing and Applications, 1-15.

[33]. El-Hay, E. A., El-Hameed, M. A., \& El-Fergany, A. A. (2018). Improved performance of PEM fuel cells stack feeding switched reluctance motor using multi-objective dragonfly optimizer. Neural Computing and Applications, 1-16.

[34]. Oshaba, A. S., Ali, E. S., \& Elazim, S. A. (2017). PI controller design via ABC algorithm for MPPT of PV system supplying DC motor-pump load. Electrical Engineering, 99(2), 505-518.

[35]. Subasi, A., Kevric, J., \& Canbaz, M. A. (2017). Epileptic seizure detection using hybrid machine learning methods. Neural Computing and Applications, 1-9.

[36]. Abdelmalek, S., Barazane, L., Larabi, A. (2017). An advanced robust fault-tolerant tracking control for a doubly fed induction generator with actuator faults. Turkish Journal of Electrical Engineering \& Computer Sciences, 25(2), 1346-1357.

[37]. Abdelmalek, S., Barazane, L., Larabi, A., \& Bettayeb, M. (2016). A novel scheme for current sensor faults diagnosis in the stator of a DFIG described by a TS fuzzy model. Measurement, 91, 680-691.

[38]. Abdelmalek, S., Azar, A. T., \& Dib, D. (2018). A novel actuator fault-tolerant control strategy of DFIG-based wind turbines using Takagi-Sugeno multiple models. International Journal of Control, Automation and Systems, 16(3), 1415-1424.

[39]. Guilbert, D., Gaillard, A., N'Diaye, A., \& Djerdir, A. (2016). Power switch failures tolerance and remedial strategies of a 4-leg floating interleaved DC/DC boost converter for photovoltaic/fuel cell applications. Renewable Energy, 90, 14-27.

[40]. Bakdi, A., Bounoua, W., Mekhilef, S., \& Halabi, L. M. (2019). Nonparametric Kullback-divergence-PCA for intelligent mismatch detection and power quality monitoring in grid-connected rooftop PV, Energy, 189, 116366. https://doi.org/10.1016/j.energy.2019.116366.

[41]. Bakdi, A., Kouadri, A., Mekhilef, S., 2019. A data-driven algorithm for online detection of component and system faults in modern wind turbines at different operating zones. Renew. Sust. Energ. Rev. 103, 546-555. 